\title{
GLYCATED LOW-DENSITY LIPOPROTEIN IN DIABETIC AND NON-DIABETIC PATIENTS
}

\author{
OMAR ABDULWAHID AL-ANI ${ }^{1 *}$, ABDURRAHMAN AL-BAZZAZ ${ }^{2}$
}

${ }^{1}$ Department of Clinical Pharmacy, Faculty of Pharmacy, Al-Rafidain University College, Baghdad, Iraq. ${ }^{2}$ Department of Pharmacy, Faculty of Pharmacy and Medical Science, Al-Ahliyya Amman University, Amman, Jordan. Email: omralani87@yahoo.com

Received: 22 November 2019, Revised and Accepted: 22 December 2019

ABSTRACT

Objective: The importance of measuring the blood level of modified low-density lipoprotein (LDL) molecules is an effective method of identifying people at risk of coronary atherosclerosis; this is because, in the early stages of atherosclerosis, lipolysis and oxidative modification have a role in promoting the uptake of these lipids through macrophages; therefore, this research aims to measure the level of glycated LDL (Gly-LDL) in the blood and its association with metabolic parameters of diabetic patients (diabetes mellitus) and non-diabetic (hyperlipidemia).

Methods: At a University Diabetes Center in Riyadh, we using routine automatic analysis methods, fasting serum samples were analyzed for 31 patients with Type-2 diabetes and 31 non-diabetic patients for LDL, high-density lipoprotein (HDL), total cholesterol, glycated hemoglobin, glucose, and triglycerides (TG), and using enzyme-linked immunosorbent assay to analyze Gly-LDL for the same sample.

Results: The level of serum Gly-LDL in non-diabetic was higher than in diabetic patients ( $p=0.037$ ). Gly-LDL level correlated significantly with LDL in the diabetic group ( $\mathrm{p}=0.035)$ and was insignificant with other parameters; moreover, it is significantly correlated with HDL ( $\mathrm{p}=0.048)$, TG ( $\mathrm{p}=0.035)$, and very LDL $(\mathrm{p}=0.03)$ in the non-diabetic group and insignificant with other parameters.

Conclusion: Measuring rates of Gly-LDL can be used in the early detection of cardiovascular disease, especially in people with diabetes, as they are more susceptible to modified and oxidized LDL.

Keywords: Hyperlipidemia, Low-density lipoprotein, Glycated low-density lipoprotein, Diabetes mellitus, Atherosclerosis.

(C) 2020 The Authors. Published by Innovare Academic Sciences Pvt Ltd. This is an open access article under the CC BY license (http://creativecommons. org/licenses/by/4. 0/) DOI: http://dx.doi.org/10.22159/ajpcr.2020.v13i2.36417

\section{INTRODUCTION}

Type 1 and Type 2 diabetes are among the most severe cases of coronary artery disease, peripheral arterial disease, and additional stroke. One of the most important causes of diabetes complications is prolonged hyperglycemia [1]. The risk of hyperglycemia is that it induces a large number of vascular tissues that can promote atherosclerosis [2], although diabetes mellitus (DM) accelerated mechanisms of atherosclerosis are considered vague [3]. The presence of high levels of glucose in DM patients leads to the creation of lipids and conditions favorable to non-enzymatic change of proteins and forming advanced glycation end products [4]. The results of the study showed that nondiabetic patients taking statins had lower serum levels of glycated lowdensity lipoprotein (Gly-LDL); this confirms that Gly-LDL occurs in all non-diabetic patients regardless of their status of glycemic [5].

Gly-LDL produced when glucose forms a covalent bond with the lysine residues of the apolipoprotein B (Apo B100), the main apolipoprotein of LDL, which is present in both diabetic and non-diabetic subjects, although it is higher in diabetic subjects more than non-diabetics ones [6].

The glycation of lipoproteins was initially reported by Schleicher et al. in 1981 [7]. Concerning normolipidemic diabetic patients confirmed with some of the presence of LDL glycation with glycemic control. In the view of Singh et al., they emphasized that glycated lipoproteins (LDL, high-density lipoprotein [HDL], and very LDL [VLDL]) contribute to atherosclerosis. By looking at the studies that are concerned with the study of the vivo and tissue culture found that physiological LDL receptors do not use to clear Gly-LDL [8] accordingly, non-Gly-LDL has a quicker catabolic rate than Gly-LDL. It is worth mentioning that recognition by LDL receptors affected by a conformational change in the binding site due to epitopes in glycation of LDL Apo B100.
Hence, we can say there is a possibility to use scavenger receptors to clear Gly-LDL on endothelial cells and macrophages [9]; this leads to the formation of foam cells and other effects in the walls of the arteries, which in turn leads to atherosclerosis, Fig. 1, this is in addition to the occurrence of glycoxidation due to modifications accrue between glycation and oxidation; it leads to generate free radicals [10]. In this study, we found that it is not necessary to increase the level of Gly-LDL in patients with diabetes compared to non-diabetic subjects because they use statin medications, and in this way, the statin lowering medications contributed to lowering the level of Gly-LDL and its use can be studied and developed for that purpose.

\section{METHODS}

Thirty-one cases of Type- 2 diabetic patients (the duration of diabetes from 5 to 15 years), and 31 non-diabetic subjects recruited in this study with age range.

Both groups show an insignificant difference when matched by age, sex, and body mass index (BMI).

- Twenty-five patients diabetic taking metformin for hyperglycemia while four patients are taking metformin with insulin, but two patients are taking sitagliptin (dipeptidyl peptidase 4) for the treatment of hyperglycemia

- $\quad$ Twenty-eight diabetic patients are taking atorvastatin (Lipitor ${ }^{\circledR}$ ), while three patients are taking simvastatin $\left(\right.$ Zocor $\left.^{\circledR}\right)$ as an antihyperlipidemia agent

- Twenty-four of the non-diabetic hypertensive subjects when taking atorvastatin (Lipitor ${ }^{\circledR}$ )

- Three subjects are taking simvastatin (Zocor®), as an antihyperlipidemia agent.

All patients sampled after an overnight fast with no medication (metformin, atorvastatin, simvastatin) taken within $24 \mathrm{~h}$. All samples 


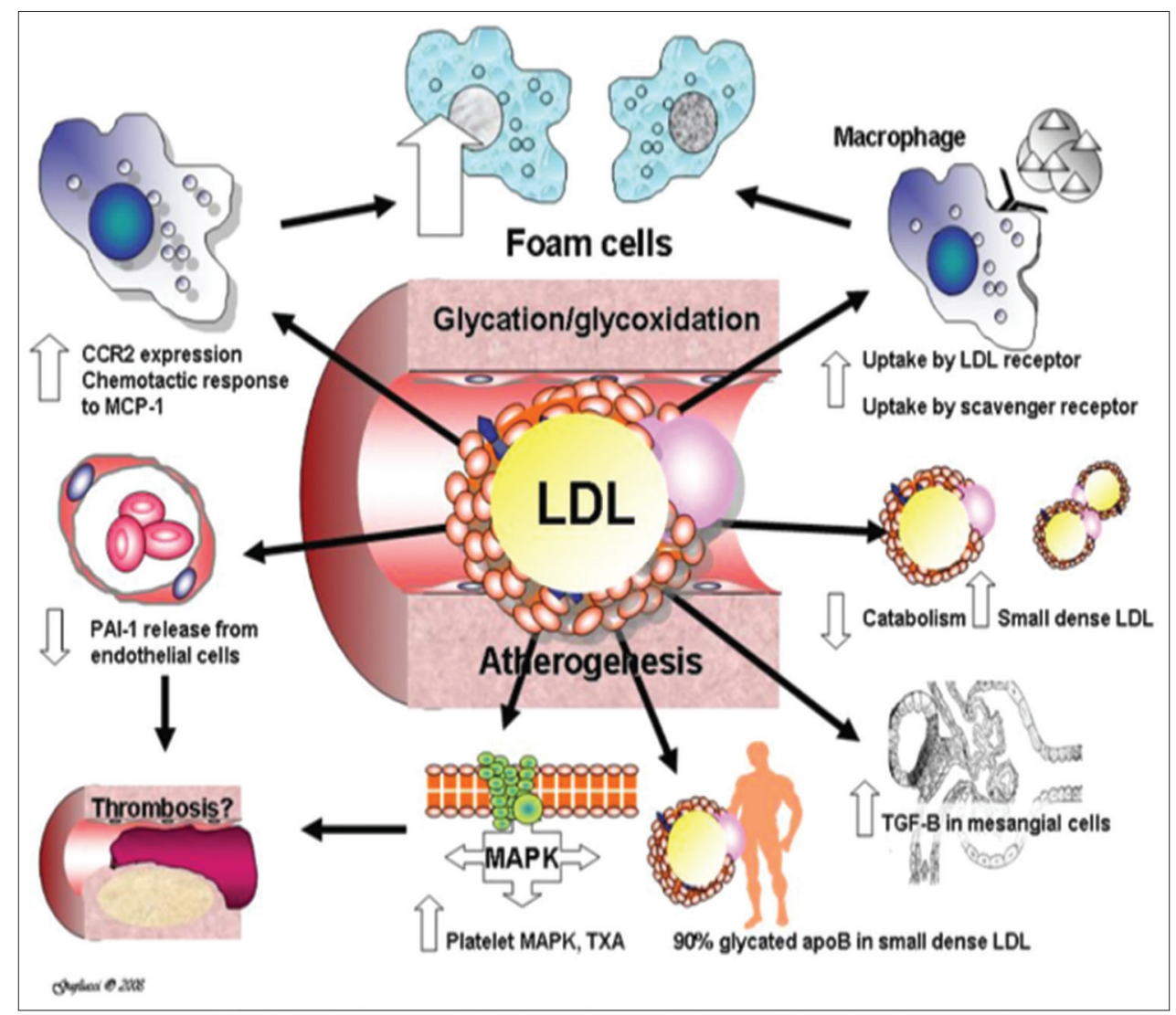

Fig. 1: The major effects of glycation of low-density lipoprotein [11]

reported to the Laboratory of Clinical Biochemistry at the Center for Strategic Diabetes Research, King Saud University, Riyadh, Saudi Arabia. The Institutional Review Board of King Saud University approved the research protocol.

The samples selected as per the inclusion and exclusion criteria; informed consent had been obtained from the subjects. A venipuncture had withdrawn $10-15 \mathrm{ml}$ of fasting (12-14 h.) blood sample. A 3-5 ml of the blood withdrawn into an ethylenediaminetetraacetic acid vacutainer; the sample stored in a cold container then centrifuged for $15 \mathrm{~min}-$ at $\times 1000 \mathrm{~g}$ at $2-8^{\circ} \mathrm{C}-$ within 30 min of collection.

After $15 \mathrm{~min}, 10 \mathrm{ml}$ of the remaining blood sample was separated and stored at low temperature $\left(-20^{\circ} \mathrm{C}\right)$ for analysis within 30 of the collection of lipid profile, fasting blood sugar (FBS), glycated hemoglobin (HbA1c), and C-reactive protein (CRP) measurements.

FBS levels, HbA1c, and lipid profiles (total cholesterol [TC], LDL, HDL, and triglycerides [TG]) measured using an accent - 200 instrument, which is an open system fully automatic clinical biochemistry analyzer with user-defined profiles and calculation chemistries, manufactured by Biotek ${ }^{\circledR}$. Sandwich enzyme-linked immunosorbent assay kits for Gly-LDL, supplied by the measuring principles depend on absorbance photometry and turbidimetry, it is resolution 0.0001 absorbance.

Using parametric and non-parametric statistics, diabetic and nondiabetic hyperlipidemic compared by analyzing the results of blood samples (lipidemic and glycemic status as standard deviation [SD]), Spearman's rank correlation coefficient used to calculate linear regression analyses between the levels of Gly-LDL, and the data maintained as mean \pm SD. Statistical analysis carried out with the SPSS 18 tool. The comparison of parameters in the study groups was made by the Student's t-test, while Pearson's correlation coefficient determined the correlation. $p<0.05$ indicated statistical significance.

\section{RESULTS}

In the comparison of essential parameters, this includes diabetic patients and non-diabetic hyperlipidemic patients' data. These data include age, BMI, Gly-LDL, LDL, HDL, TC, TG, VLDL, TG/HDL, CRP, $\mathrm{HbA1c}$, and FBS. The groups of the study sample were not the same age and BMI was somewhat similar in each group. In the hyperlipidemic patients, the levels of HDL, TC, TG/HDL, CRP, Gly-LDL, and LDL were higher. On the other hand, the levels of HBA1c, VLDL, and TG were higher in diabetic subjects. The levels of HDL, LDL, and Gly-LDL were higher in the non-diabetic hyperlipidemic patient than in diabetic patients where $(p=0.037),(p=0.018)$, and $(p=0.044)$ respectively. The correlation between levels of Gly-LDL and parameters were used in two groups to illustrate the correlation between the concentration of Gly-LDL and the concentration of other parameters. We concluded that there is a positive correlation between Gly-LDL and HbA1c, TC, FBS, TG, LDL, VLDL, and TG/HDL, a significant correlation only noticed with LDL ( $p=0.035$ ); however, a negative correlation observed with HDL and CRP in the diabetic group. In the non-diabetic hyperlipidemic group, Gly-LDL correlated negatively with HDL ( $\mathrm{p}=0.048)$ and positively with other measured parameters, in this group Gly-LDL only significantly correlated with HDL ( $\mathrm{p}=0.048)$, TG ( $\mathrm{p}=0.035)$, and VLDL $(\mathrm{p}=0.031)$.

\section{DISCUSSION}

The presence of hyperlipidemia has a severe role in increasing the chances of developing coronary heart disease (CHD) [12-20]. Furthermore, there are physical and biochemical factors that increase the chances of developing CHD in people with DM than others, namely, lipoproteins, where lipoproteins differ in those with diabetes than those without diabetes. This difference is due to high blood sugar, changes in electrical charge, variable Apo B receptor binding, lipid synthesis changes, reduced effectiveness in suppressing intracellular cholesterol synthesis, and reduced absorption of ApoB containing lipoproteins [21-23]. All of these lead to a higher risk of CHD through 
atherosclerosis due to the accumulation of lipoprotein in vivo [21,23]. The presence of the Gly-LDL increases the production of superoxide anions in macrophages, and the synthesis of prostaglandins in cell types, increasing the risk of atherosclerosis [23]. Due to these different processes, LDL is efficiently uptake by macrophages $[22,23]$. All of these leading to enhance the platelet agreeability and accelerating the formation of a foam cell $[21,23]$. In the theoretical view, we find that an increase in blood lipid levels, which in turn enhances the uptake of these lipids through macrophages in hyperlipidemia patients due to high rates of lipoprotein glycation. Therefore, the formation of foam cells should be promoted in the early stages of atherosclerosis. If we can quantify the modified lipid particles, we should identify an index of the joint atherogenicity of glycemia and lipidemia and thus devise other effective methods for identifying subjects. The result was that the level of Gly-LDL was higher in people with hyperlipidemia, more and the non-diabetic than in the diabetic ones. There is a positive correlation between Gly-LDL and HbA1c, TC, FBS, TG, LDL, VLDL, and TG/HDL; a significant correlation only noticed with LDL $\left(\mathrm{p}=0.035^{*}\right)$; however, a negative correlation was observed with HDL and CRP in the diabetic group in Table 1. Furthermore, positive correlations with glucose, HbA1c, TC, TG, VLDL, and LDL, significant correlation only with TG and VLDL $\left(\mathrm{p}=0.035^{*}\right)$ and $\left(\mathrm{p}=0.031^{*}\right)$, and a negative one with HDL, TG/HDL, and CRP only significant with HDL $\left(p=0.048^{*}\right)$ in the non-diabetic hyperlipidemic group.

In diabetes, the Gly-LDL level may be higher if the levels of LDL are raised [22]; besides, the level of Gly-LDL is an essential modification of atherosclerosis of LDL. Much research needs to find an explanation for the negative results of clinical trials that seek to show a reduced risk of cardiovascular disease while improving blood sugar control [23], compared to that reduced LDL with statin treatment. The results of this study showed significantly $(\mathrm{p}=0.035)$ higher mean \pm SD serum level of

Table 1: Correlation between levels of Gly-LDL and parameters in the study

\begin{tabular}{lll}
\hline Gly-LDL V.S & Diabetic group & Non-diabetic \\
\hline LDL & $0.035^{*}$ & 0.431 \\
HDL & $0.945(-$ ve correlation) & $0.048^{*}$ (-ve correlation) \\
TC & 0.057 & 0.579 \\
TG & 00.748 & $0.035^{*}$ \\
VLDL & 0.648 & $0.031^{*}$ \\
TG/HDL & 0.489 & 0.495 (-ve correlation) \\
CRP & $0.406(-$ ve correlation) & 0.955 (-ve correlation) \\
HbA1c & 0.377 & 0.893 \\
FBS & 0.247 & 0.214 \\
\hline
\end{tabular}

N: Number of subjects=31, ${ }^{*} \mathrm{p}<0.05$. Gly-LDL: Glycated low-density

lipoprotein, LDL: Low-density lipoprotein, HDL: High-density lipoprotein,

TC: Total cholesterol, TG: Triglyceride, VLDL: Very low-density lipoprotein

TG/HDL: Triglyceride/high-density lipoprotein, CRP: C-reactive protein,

HbA1c: Glycated hemoglobin, FBS: Fasting blood sugar
Gly-LDL in the non-diabetic hyperlipidemic group $(5.03 \pm 1.69 \mu \mathrm{mol} / \mathrm{ml})$ as compared with the mean \pm SD serum level of Gly-LDL in the diabetic group $(4.09 \pm 1.76 \mu \mathrm{mol} / \mathrm{ml}$ ) (Table 2). This high level of Gly-LDL with low levels of LDL in the diabetic group is in agreement with the study of Tames et al. [24]. Furthermore, the results showed significantly ( $p=0.018$ ) higher mean \pm SD serum level of LDL in the nondiabetic hyperlipidemic group $(131.522 \pm 32.52 \mathrm{mg} / \mathrm{dL})$ as compared with the mean \pm SD serum level of LDL in their diabetic patients $(111.72 \pm 31.65 \mathrm{mg} / \mathrm{dL})$ in Table 2, represent significantly $(\mathrm{p}=0.04)$ higher mean \pm SD serum level of TC in the non-diabetic hyperlipidemic group $(185.3 \pm 30.72 \mathrm{mg} / \mathrm{dL})$ as compared with the mean \pm SD serum level of TC in their diabetic patients $(169.67 \pm 29.01 \mathrm{mg} / \mathrm{dL})$. Younis et al. showed that in non-diabetic people, small-dense LDL (SD-LDL) is more heavily glycated than other ApoB-containing lipoproteins; this can be due to increased surface exposure to lysine residues from ApoB in smaller LDL molecules (SD-LDL) [10]. Through the concentration of SD-LDL, we can determine the total plasma concentration of Gly-LDL strongly; this may be the reason for the high levels of Gly-LDL in diabetic patients who do not receive statin treatment [25]. Diabetic patients had a higher proportion of their plasma ApoB in SD-LDL than either multiple sclerosis (MS) or DM patients with a statin [26].

In DM patients, the rate of Gly-LDL in SD-LDL was higher than in large bayonet LDL; this may increase the risk of increased cardiovascular disease in MS and persisting risk in statin-treated patients [27].

Non-diabetic, normolipidemic people and those with frank diabetes appear to have an intermediate phenotype, MS; this emphasizes the correlation between plasma Gly-LDL concentration and CHD risk [10]. Michele et al. showed that the correlation between SD-LDL and plasma Gly-LDL was stronger than that with HbA1c in both diabetics and MS. While in other research, Gly-ApoB did not show any correlation with glycemic indices [24].

According to Lee et al., it is possible to find a correlation between glycemia and concentration of SD-LDL, where the concentration of SDLDL considered on indices of glycemia in non-statin-treated Type-2 diabetes [28-30]. Although the level of LDL in both groups was within acceptable ranges, the high indication could be in the modified type of LDL in a way that the SD-LDL will be higher, as confirmed in our study by the TG/HDL ratio. Data of the research illustrated insignificantly lower $(p=0.484)$ mean \pm SD serum level of TG/HDL ratio in diabetic $(3.13 \pm 1.75)$ as compared with the mean $\pm \mathrm{SD}$ serum level of TG/HDL in the nondiabetic hyperlipidemic group (3.5 \pm 2.37$)$. Research data showed insignificantly lower $(p=0.21)$ mean \pm SD serum level of HDL in diabetic patients $(42.51 \pm 8.25 \mathrm{mg} / \mathrm{dL})$ as compared with the mean \pm SD serum level of HDL in non-diabetic (hyperlipidemic) group $(45.42 \pm 9.75 \mathrm{mg} / \mathrm{dL})$ Table 2. Under the condition of hyperglycemia, the glycation of HDL can affect the activity of paraoxonase, where the presence of glycation of HDL can reduce it. Paraoxonase activity is an HDL-associated ester hydrolase, which is very important to prevent LDL oxidation. In a

Table 2: Comparison of basic parameters

\begin{tabular}{|c|c|c|c|c|}
\hline Parameters & Diabetic & Non-diabetic & p-value & Normal range \\
\hline Age (year) & $49 \pm 6.9$ & $46 \pm 8.9$ & 0.17 & -- \\
\hline BMI $\left(\mathrm{kg} / \mathrm{m}^{2}\right)$ & $31.8 \pm 6.9$ & $36.5 \pm 6.2$ & 0.47 & --- \\
\hline Glycated LDL $(\mu \mathrm{mol} / \mathrm{ml})$ & $4.09 \pm 1.7$ & $5.03 \pm 1.6$ & $0.037^{*}$ & $<2.5$ \\
\hline $\mathrm{LDL}(\mathrm{mg} / \mathrm{dl})$ & $111.7 \pm 31.6$ & $131.5 \pm 32.5$ & $0.018^{*}$ & $100-130$ \\
\hline HDL (mg/dl) & $42.5 \pm 8.2$ & $45.4 \pm 9.7$ & 0.21 & $40-60$ \\
\hline $\mathrm{TC}(\mathrm{mg} / \mathrm{dl})$ & $169.6 \pm 29.01$ & $185.3 \pm 30.7$ & $0.044^{*}$ & $<200$ \\
\hline TG (mg/dl) & $144.1 \pm 77.8$ & $129.3 \pm 61.9$ & 0.414 & $<150$ \\
\hline TG/HDL ratio & $3.1 \pm 1.7$ & $3.5 \pm 2.3$ & 0.484 & $<3$ \\
\hline CRP (mg/L) & $0.39 \pm 0.47$ & $0.59 \pm 0.62$ & 0.32 & $0.1-0.3$ \\
\hline HbA1c (\%) & $9 \pm 0.018$ & $5 \pm 0.009$ & $0.000 *$ & $<6$ \\
\hline FBS (mg/dl) & $177 \pm 69.09$ & $95 \pm 20.2$ & $0.000^{*}$ & $70-100$ \\
\hline
\end{tabular}

Significant if the ${ }^{*} \mathrm{p}=0.05$, SD: Standard deviation, N: Number of sample=31, HbA1c: Glycated hemoglobin, BMI: Body mass index, FBS: Fasting blood sugar, TC: Total cholesterol, LDL: Low-density lipoprotein, VLDL: Very low-density lipoprotein, HDL: High-density lipoprotein, TG: Triglycerides, CRP: C-reactive protein 
previous study [30], it found that a $65 \%$ decrease in the activity of paraoxonase after observation of the presence of glycation of HDL in the sample. Furthermore, the reduction in glycated HDL and paraoxonase levels prevents monocyte adhesion to aortic endothelial cells. These are the first events with which the development of atherosclerosis begins [8]. HDL acts as a scavenger; it was observed within low levels in diabetic and non-diabetic groups, as shown in Tables 1 and 2, which demonstrates that there is an insignificant correlation between Gly-LDL and HDL levels in the diabetic group, while a significant correlation in the non-diabetic (hyperlipidemic) group observed.

\section{CONCLUSION}

- For non-diabetic (hyperlipidemic) patients, the levels of serum Gly-LDL increased. On the other hand, the levels of serum Gly-LDL reduced in diabetic patients who took a statin. We conclude that in all hyperlipidemic patients, the Gly-LDL occurs regardless of their status of glycemic

- The apparent correlation between LDL and Gly-LDL, it can be used as an indicator of controlling the glycemic in diabetic patients

- Measuring rates of Gly-LDL helps to know more about the possibility of a person infection of coronary heart disease.

\section{ACKNOWLEDGMENT}

The authors thank King Saud University/University Diabetic Center for supporting the project.

\section{AUTHORS' CONTRIBUTIONS}

Dr. Abdulrahman Al-Bazzaz - contributed to the selection of the topic, research concept development, and guided the research process and manuscript preparation. Dr. Omar A. Al-Ani - conducted the study, participated in data processing, conducted the study, and participated in data collection and manuscript writing.

\section{CONFLICTS OF INTEREST}

The authors declare that they have no conflicts of interest.

\section{REFERENCES}

1. Mohsin A, Sana A, Syed I, Mohammed A, Mohd A. Continuous Glucose Monitoring (CGM) technology: Current challenges and future promises for a better diabetic lifestyle. Hum J 2017;9:190-83.

2. Doron A, Elliot J. How hyperglycemia promotes atherosclerosis: Molecular mechanisms. Cardiovasc Diabetol 2002;1:136-27.

3. Samer M, Wael W, Saad H. Effects of a combination therapy with atorvastatin and metformin on the glycemic control and adiposity indices in newly diagnosed overweight patients with Type -2 diabetes mellitus. Asian J Pharm Clin Res 2018;11:209-13.

4. Isoda K, Folco E, Marwali MR, Ohsuzu F, Libby P. Glycated LDL increases monocyte $\mathrm{CC}$ chemokine receptor 2 expression and monocyte chemoattractant protein-1-mediated chemotaxis. Atherosclerosis 2008;198:307-12.

5. Tooba L, Qureshi SA. Centratherum anthelminticum and Withania coagulans improves lipid profile and oxidative stress in triton X-100 induced hyperlipidemic. Int J Pharmacogn Phytochem Res 2016;8:940-33.

6. Misciagna G, Logroscino G, De Michele G, Guerra V, Cisternino AM, Caruso MG, et al. Glycated apolipoprotein B and myocardial infarction. Nutr Metab Cardiovasc Dis 2007;17:6-12.

7. Schleicher E, Deufel T, Wieland OH. Non-enzymatic glycosylation of human serum lipoproteins. Elevated epsilon-lysine glycosylated low density lipoprotein in diabetic patients. FEBS Lett 1981;129:1-4.

8. Singh R, Barden A, Mori T, Beilin L. Advanced glycation end-products. Diabetologia 2001;24:146-29.
9. Younis N, Sharma R, Soran H, Charlton-Menys V, Elseweidy M, Durrington PN. Glycation as an atherogenic modification of LDL. Curr Opin Lipidol 2008;19:384-78.

10. Younis N, Soran H, Hassanein M. Cardiovascular disease and intensive glucose lowering in Type 2 diabetes. QJM 2009;102: 293-396

11. Hermo R, Mier C, Mazzotta M, Tsuji M, Kimura S, Gugliucci A. Circulating levels of nitrated apolipoprotein A-I are increased in Type 2 diabetic patients. Clin Chem Lab Med 2005;43:601-6

12. Haffner SM, Lehto S, Rönnemaa T, Pyörälä K, Laakso M. Mortality from coronary heart disease in subjects with Type 2 diabetes and in nondiabetic subjects with and without prior myocardial infarction. N Engl J Med 1998;339:229-34.

13. American Diabetes Association. Position statement. Management of dyslipidaemia in adults with diabetes. Diabetes Care 1998;21:179-82.

14. Dean JD, Durrington PN. Treatment of dyslipoproteinaemia in diabetes mellitus. Diabet Med 1996;13:297-312.

15. Garg A. Management of dyslipidemia in IDDM patients. Diabetes Care 1994;17:224-34.

16. Syvanne M, Taskinen M. Lipids and lipoproteins as coronary risk factors in non-insulin dependent diabetes mellitus. Lancet 1997;350 Suppl 1:20-3.

17. Expert Panel on Detection, Evaluation, and Treatment of High Blood Cholesterol in Adults. Executive Summary of the Third Report of the National Cholesterol Education Program (NCEP) expert panel on detection, evaluation, and treatment of high blood cholesterol in adults (Adult Treatment Panel III). JAMA 2001;285:2486-97.

18. Expert Panel on Detection, Evaluation, and Treatment of High Blood Cholesterol in Adults. Summary of the second report of the National Cholesterol Education Program (NCEP) expert panel on detection, evaluation, and treatment of high blood cholesterol in adults (Adult Treatment Panel II) JAMA 1993;269:3015-23.

19. Brown WV. Lipoprotein disorders in diabetes mellitus. Med Clin North Am 1994; 78:143-61

20. Stehouwer CD, Schaper NC. The pathogenesis of vascular complications of diabetes mellitus: One voice or many? Eur J Clin Invest 1996;26:535-43

21. Krämer-Guth A, Quaschning T, Galle J, Baumstark MW, Königer M, Nauck M, et al. Structural and compositional modifications of diabetic low-density lipoproteins influence their receptor-mediated uptake by hepatocytes. Eur J Clin Invest 1997;27:460-8

22. Graier WF, Kostner GM. Glycated low-density lipoprotein and atherogenesis: The missing link between diabetes mellitus and hypercholesterolaemia? Eur J Clin Invest 1997;27:457-9.

23. Pentikäinen MO, Oörni K, Ala-Korpela M, Kovanen PT. Modified LDL trigger of atherosclerosis and inflammation in the arterial intima. J Int Med 2000;247:359-70.

24. Tames FJ, Mackness MI, Arrol S, Laing I, Durrington PN. Nonenzymatic glycation of apolipoprotein B in the sera of diabetic and nondiabetic subjects. Atherosclerosis 1992;93:237-44.

25. Action to Control Cardiovascular Risk in Diabetes Study Group, Gerstein HC, Miller ME, Byington RP, Goff DC Jr., Bigger JT, et al. Effects of intensive glucose lowering in Type 2 diabetes. N Engl J Med 2008:358:2545-59

26. Panteghini M, Cimino A, Pagani F, Girelli A. Non-enzymicglycation of apolipoprotein B in patients with insulin- and noninsulin-dependent diabetes mellitus. Clin Biochem 1995;28:592-87.

27. Malik S, Wong ND, Franklin SS, Kamath TV, L'Italien GJ, Pio JR, et al. Impact of the metabolic syndrome on mortality from coronary heart disease, cardiovascular disease, and all causes in United States adults. Circulation 2004;110:1245-50.

28. Lee W, Min WK, Chun S, Jang S, Kim JQ, Lee DH, et al. Low-density lipoprotein subclass and its correlating factors in diabetics. Clin Biochem 2003;36:657-61.

29. Elmurugan C, Anurag B. Anti-diabetic and hypolipidemic activity of fruits of Pyrus communis L in hyperglycemic rats. Asian J Pharm Clin Res 2013;6:108-11.

30. Hedrick CC, Thorpe SR, Fu MX, Harper CM, Yoo J, Kim SM, et al. Glycation impairs high-density lipoprotein function. Diabetologia 2000;43:312-20. 